\title{
Optimization of Crude Oil Biodegradation of Fungi Isolated from Refinery Effluent Site using Response- Surface Methodology
}

\author{
U. C. Odili ${ }^{1}$, F. B. Ibrahim
, E. M. Shaibu-Imodagbe
, H. I. Atta
}

ABSTRACT: The activities involved in the production and exploration of crude oil has constantly polluted the environment. This study investigated the ability of an indigenous fungus to utilize petroleum hydrocarbon. Response Surface Methodology was used to optimize the effects of $\mathrm{pH}$, microbial concentration (spores/ml), and contact time (days) on the crude oil removal efficiency in refinery effluent. Monocillium sp. was isolated and used for the treatment of refinery effluent due to its predominance in the contaminated soil. Twenty experimental runs were analyzed to determine the effect of $\mathrm{pH}$, microbial concentration and contact time on the oil removal efficiency. From the experimental results obtained, a maximum oil removal efficiency of $98.42 \%$ was achieved at a pH of 6.5 , contact time of 14 days, and a microbial concentration of 3 spores $/ \mathrm{ml}$. The results obtained showed the percentage of crude oil removal in the effluent sample increased with an increase in time. Optimization of the experimental result was achieved at a removal efficiency of $98.59 \%$, a contact time of 13.96 days, a $\mathrm{pH}$ of 6.85 , and a microbial concentration of 3.01 spores $/ \mathrm{ml}$. The findings of this study revealed that Monocillium sp. is a viable hydrocarbon degrader, and can be used in the bioremediation of petroleum contaminated environments.

Keywords: Response surface, optimization, bioremediation, hydrocarbon, removal efficiency, Monocillium sp.

[Received May 22, 2020, Revised July 31, 2020, Accepted August 8, 2020]

Print ISSN: 0189-9546 | Online ISSN: 2437-2110

\section{INTRODUCTION}

Increase in petroleum-related pollution and degradation of the environment over the past few decades have resulted from the continuous use of fossil fuels (McDonald, 2001; Nwachi et al., 2013). Oil exploration and exploitation have greatly contributed to the growth of the economy but, these have also led to several incidences of oil spills into the environment leading to contamination of soil and water bodies (Onifade $e t$ al., 2007; Olukunle and Oyegoke, 2016; Barnes et al., 2018).

To effectively tackle oil pollution in water in recent times, some technologies such as the use of absorbents (clay and straws), dispersants, the use of booms and skimmers, oil skimming agents, and oil coagulation have also been investigated (Wilde, 2017). However, these physical and chemical treatment processes are expensive, and also leave byproducts that are either incinerated or buried leading to air pollution and groundwater pollution as the case may be (AbdelRahman, 2011; Nilanjana and Preethy, 2011). Biological treatment is the use of microorganisms to clean up oil-contaminated sites; and, it is preferred to physical and chemical treatments because it is sustainable, environment friendly, non-toxic, biodegradable, and requires low cost (Ajani et al., 2017; Al-Hawash et al., 2018).

Biodegradation refers to the use of microbes to reduce complex organic pollutants to smaller chemical compounds (Joutey et al., 2013). These organisms utilize organic pollutants as their sole carbon source and can break down these compounds due to the type of enzymes produced. These enzymes oxidize a wide range of hydrocarbons (Raji, 2016).

Microorganisms such as bacteria, algae, yeast, and some fungi have been reported to be hydrocarbon degraders (Ibrahim, 2008; Nilanjana and Preety, 2011; Joutey et al., 2013; Al-Hawash et al., 2018). Fungi are known to be good hydrocarbon degraders due to the nature of extracellular enzymes they produce. These enzymes make it easy for the fungi to assimilate complex carbohydrates thereby degrading a wide range of pollutants (Nilanjana and Preethy, 2011; Raji, 2016). Some hydrocarbon-degrading fungi are, Alternaria, Aspergillus, Candida, Cephalosporium, Cladosporium, Fusarium, Geotrichum, Gliocladium, Mucor, Paecilomyces, Penicillium, Pleurotus, Polyporus, Rhizopus, and Rhodoto (Nilanjana and Preethy, 2011; Joutey et al., 2013).

Indigenous microorganisms have played a significant role in the biodegradation of crude oil due to their ease of adaptation to environments that require treatment (AlHawash et al., 2018). Many studies have been conducted on the isolation and characterization of hydrocarbon degraders from oil spill sites. Their findings revealed that hydrocarbondegrading organisms are abundant in the soil and can be exploited for use in the treatment of hydrocarbon polluted sites (Onifade et al., 2007; Ibrahim, 2008; Olabisi et al., 2009; 
Abdel Rahman, 2011; Nilanjana and Preethy, 2011; Isaac, 2018; Orjiude, 2018).

Response surface methodology (RSM) is a collection of mathematical and statistical techniques for empirical modeling. The objective of the RSM is to optimize a response (output variable) which is influenced by several independent variables (input variable) (Montgomery, 2009). Optimization techniques in bioremediation are used to evaluate the interaction effects of process parameters on removal efficiency and not so much work has been reported on this. RSM has been used in recent times to study the effects of time, organic fertilizer, palm kernel oil and commercial activated carbon as biostimulating agents in remediation of contaminated soil (Ajani et al., 2017), to assess and optimize ex-situ bioremediation of petroleum-contaminated soil under cold climatic conditions (Francisco, 2014), enhanced bioremediation of soil artificially contaminated with weathered bonny light crude oil (Agarry and Ogunleye, 2012). This research is therefore aimed at developing an efficient technique for the treatment of oil in refinery effluent by investigating the best response surface design using response surface methodology.

\section{MATERIALS AND METHODS \\ A. Sample Collection and Isolation}

Soil samples contaminated with crude oil were collected randomly from five different points from a refinery effluent site at depths of $0-15 \mathrm{~cm}$. The samples were collected using a sterile spatula and placed in clean ziplock bags. The samples were stored in an icebox to preserve the samples. In the laboratory, stones and debris were removed using a $2 \mathrm{~mm}$ sieve (Prenafeta-Boldu et al., 2001). Wastewater effluents were also collected from the wastewater treatment plant of the Kaduna refinery in a $25 \mathrm{~L}$ container by filling the container with a sampling bucket and transported to the Environmental Health Laboratory of Ahmadu Bello University Zaria for further analysis.

Monocillium sp. was isolated from the hydrocarbon contaminated soil using enrichment technique with the following composition: $\mathrm{Na}_{2} \mathrm{HPO}_{4}(0.2 \mathrm{~g}), \mathrm{K}_{2} \mathrm{SO}_{4}(0.017 \mathrm{~g})$, $\mathrm{NH}_{4} \mathrm{NO}_{3}(0.4 \mathrm{~g}), \mathrm{KH}_{2} \mathrm{PO}_{4}(0.053 \mathrm{~g}), \mathrm{MgSO}_{4} .7 \mathrm{H}_{2}(0.05 \mathrm{~g})$ as described by Nwachukwu (2000). The salts were dissolved in $100 \mathrm{ml}$ of distilled water and sterilized by autoclaving at 121 ${ }^{0} \mathrm{C}$ for 15 mins (Ekundayo et al., 2012). In this method, soil samples (approximately $5 \mathrm{~g}$ ) were suspended in $100 \mathrm{ml}$ of already prepared Mineral Salt Medium and $0.025 \mathrm{~g}$ of chloramphenicol and $1 \%$ pure crude oil as the sole carbon source was added to it and closed with a tight lid. The flask was placed in a mechanical shaker (SHA-C, China) at $130 \mathrm{rpm}$ and incubated for 7 days at $28{ }^{\circ} \mathrm{C}$ (Prenafeta-Boldu et al., 2001). A 10 -fold serial dilution was carried out and $1 \mathrm{ml}$ of each dilution was poured into duplicate Potato Dextrose Agar (PDA) plates for the isolation of crude oil utilizing fungi. The plates were incubated at $28{ }^{\circ} \mathrm{C}$ for 7 days (AbdelRahman, 2011).

\section{B. Bioremediation of Refinery Effluent using Monocillium sp.}

The mineral salt medium was prepared as previously described but untreated effluent was used as the solvent instead of distilled water. The effluent medium was dispensed into each of twenty (20) $250 \mathrm{ml}$ Erlenmeyer flask set up in triplicates and a control flask containing only the untreated effluent and were sterilized by autoclaving at $121{ }^{\circ} \mathrm{C}$ for 15 mins. The flasks were inoculated with $3 \mathrm{ml}$ and $5 \mathrm{ml}$ suspensions of the isolates of Monocillium sp. The setup was incubated at ambient temperature on a rotary shaker at $150 \mathrm{rpm}$ (El-Sheshtawy et al., 2017) for the duration of 7 and 14 days respectively. After each interval of incubation, a set of the experiment was analyzed for oil removal efficiency. The residual oil and grease (hydrocarbons) were determined using the petroleum ether extraction method (Orjiude, 2018).

\section{C. $2^{3}$ Factorial Design Matrix}

Statistical analysis of the experimental data was used to optimize the bioremediating efficiency of Monocillium sp. to maximize oil removal using Design Expert software. A $2^{3}$ a factorial design was employed and the factors that were optimized are $\mathrm{pH}$, microbial concentration (spores $/ \mathrm{ml}$ ), and contact time (days) labeled as $\mathrm{A}, \mathrm{B}$, and $\mathrm{C}$ respectively. The experimental design plan selected for this study was the central composite design (CCD) with three factors at two levels. The models developed for removal efficiency are presented in terms of actual and coded factors in Eqs. (1) and (2). The equation in terms of coded factors in Eq. (1) was used to make predictions by identifying the relative impact of the factors usually by comparing the factor coefficients. The equation in terms of the actual factors (see Eq. (2)) is a predictive model used to recreate the of this experiment (Montgomery, 2009; Adebisi 2016).

$$
\begin{aligned}
& E_{R}=+86.86+1.42 A+0.85 B+8.60 C+0.52 A B- \\
& 1.10 A C-6.89 B C+3.00 A^{2}-0.51 B^{2}-4.38 C^{2} \\
& \text { where: } \\
& \quad \text { A - pH } \\
& \quad \text { B - Microbial concentration (spores } / \mathrm{ml}) \\
& \quad \text { C - Contact time (days) } \\
& \quad E_{R}=+76.47434-42.39988 A+21.70612 B+ \\
& 20.20056 C+0.51750 A B-0.31500 A C-1.96929 B C+ \\
& \quad 3.00361 A^{2}-0.50718 B^{2}-0.35729 C^{2}
\end{aligned}
$$

The model developed for this study was investigated using design expert version 7.0.0 software. The software analyzed the responses of each through the fit-summary, model selection analysis of variance (ANOVA), model diagnostics, model graph for 3-D and contour plots, and also the Box-Cox plot. The model reduction was also carried out to adjust the model as presented in Table 4.

The adequacy of the model was verified with the analysis of error (residual) behaviour of the data. These errors or residuals are the differences between the actual observations and the fitted values from the regression model (Montgomery, 2009). According to Montgomery (2009), for a model to be adequate, the residual of the data should be normally distributed, unstructured (randomly distributed) with constant variance and zero mean. The studentized residual was used to carry out model adequacy tests because it is able to analyze a wide range of data that might have a high influence on the least-squares fit. 


\section{RESULTS AND DISCUSSION}

The indigenous fungal isolate used in this study, (Monocillium sp.) was predominant in the soil contaminated with crude oil from a refinery effluent site. This selection was made based on the results obtained from screening during biodegradation studies, the results showed that among all isolates screened, Monocillium sp. had the highest ability to grow on oil agar, the highest weight loss of crude oil and also the highest HUF counts. The ability of this isolate to achieve better results than the others may be because it has more active enzymatic capabilities (Raji, 2016).

Fungi have been reported to play an important role in the biodegradation of crude oil due to the extracellular enzymes they produce which helps to break down organic matter or recalcitrant hydrocarbon molecules into simpler nutrition of the fungi (Ekundayo et al., 2012; Olukunle and Oyegoke, 2016). Monocillium sp. also had the ability to form better spores which improved its ability to utilize crude oil as its sole carbon source (April et al., 2000; Mittal and Singh, 2009; Majekodunmi, and Adongbede, 2016).

\section{A. Responses from the Removal Efficiency of Crude Oil}

The response (Removal Efficiency) was calculated after running the laboratory experiments as presented in Table 1. This shows the outcome of the experimental runs carried out in the laboratory using CCD. The output response was outlined for further analysis using ANOVA. This performance was evaluated with the second-order model to establish the optimization process (Montgomery, 2009).

Table 1: Central Composite Design (CCD) Matrix and Output Response for Bioremediation of Oil Contaminated Effluent.

\begin{tabular}{cccccc}
\hline Run & Factor A: pH & $\begin{array}{c}\text { Factor B: Microbial } \\
\text { Concentration (spores/ml) }\end{array}$ & $\begin{array}{c}\text { Factor C: } \\
\text { Contact time } \\
\text { (days) }\end{array}$ & $\begin{array}{c}\text { Response: removal } \\
\text { efficiency }\end{array}$ & $\begin{array}{c}\text { Standard } \\
\text { Error } \\
( \pm)\end{array}$ \\
\hline 1 & & 4 & 10.5 & 85.57 & 0.420 \\
2 & 7.5 & 4 & 10.5 & 90.50 & 0.445 \\
3 & 7.5 & 5 & 7 & 90.34 & 0.451 \\
4 & 8.5 & 3 & 14 & 96.83 & 0.475 \\
5 & 8.5 & 5 & 14 & 83.87 & 0.090 \\
6 & 6.5 & 3 & 7 & 62.44 & 0.305 \\
7 & 6.5 & 4 & 10.5 & 84.27 & 0.415 \\
8 & 7.5 & 3 & 7 & 75.25 & 0.369 \\
9 & 8.5 & 4 & 10.5 & 86.62 & 0.425 \\
10 & 7.5 & 5 & 7 & 85.45 & 0.419 \\
11 & 6.5 & 5 & 14 & 94.34 & 0.462 \\
$\mathbf{1 2}$ & 8.5 & $\mathbf{3}$ & $\mathbf{1 4}$ & $\mathbf{9 8 . 4 2}$ & $\mathbf{0 . 4 8 2}$ \\
13 & $\mathbf{6 . 5}$ & 4 & 16.4 & 90.00 & 0.441 \\
14 & 7.5 & 4 & 10.5 & 87.49 & 0.429 \\
15 & 7.5 & 2.3 & 10.5 & 86.65 & 0.425 \\
16 & 7.5 & 5.7 & 10.5 & 81.05 & 0.397 \\
17 & 7.5 & 4 & 10.5 & 91.63 & 0.449 \\
18 & 9.2 & 4 & 10.5 & 95.93 & 0.470 \\
19 & 5.8 & 4 & 10.5 & 86.88 & 0.426 \\
$\mathbf{2 0}$ & 7.5 & $\mathbf{4}$ & $\mathbf{4 . 6}$ & $\mathbf{5 5 . 8 1}$ & $\mathbf{0 . 2 7 4}$ \\
\hline
\end{tabular}

The results obtained in Table 1 indicate that the addition of microorganisms increased the removal efficiency of crude oil in the effluent sample (Abdullah et al., 2014). The maximumA. removal efficiency was $98.42 \%$ (at $\mathrm{pH}=6.5$, contact time $=B$. 14 days, and microbial concentration $=3$ spores $/ \mathrm{ml}$ ), while the minimum removal efficiency obtained was $55.81 \%$ (at $\mathrm{pH}=$ 7.5 , contact time $=4.61$ days, and microbial concentration $=4$ spores/ml). It was observed that contact time had the most effect on the removal efficiency as the highest removal efficiencies of crude oil was obtained at day 14 as in the cases of Run 4, Run 11, and Run 12 having removal efficiencies of $96.83 \%, 94.34 \%$, and 98.42 \%. Agarry and Jimoda (2013), Ajani et al., (2017) also reported the strong influence of time on petroleum hydrocarbon degradation. Also, Run 20 had the least removal efficiency of crude oil and also a low contact time or incubation period of 4 days.

\section{B. Fit Summary Statistics}

The fit summary presents a summary of calculated data and test results for all distributions to fit the model. This model fits the data into first-order or linear, linear with interaction, second-order, and cubic equations (Montgomery, 2009). Table 2 shows the highest order polynomial selected from the fit summary analysis. This fit summary suggests both linear and quadratic models with significant terms. $P$-values less than 0.05 suggest that the model is significant (Francisco, 2014; Adebisi, 2016). The quadratic model with an F-value of 5.55 at $P \leq 0.0235$ shows that the model is significant and therefore selected for further analysis. 
Table 2: Fit Summary for Removal Efficiency.

\begin{tabular}{|c|c|c|c|c|c|c|c|}
\hline Source & $\begin{array}{c}\text { Sum of } \\
\text { Squares }\end{array}$ & Df & $\begin{array}{c}\text { Mean } \\
\text { Square } \\
\end{array}$ & $\begin{array}{c}\mathbf{R}^{2} \\
\text { Value }\end{array}$ & F Value & $\begin{array}{c}p- \\
\text { value } \\
\text { Prob > } \\
\text { F } \\
\end{array}$ & \\
\hline Mean & 146092.16 & 1 & $\begin{array}{c}146092.1 \\
6\end{array}$ & & & & \\
\hline $\begin{array}{l}\text { Block vs } \\
\text { Mean }\end{array}$ & 32.59 & 2 & 16.30 & & & & \\
\hline Linear & 1047.94 & 3 & 349.31 & & 4.62 & 0.0290 & Suggested \\
\hline $\begin{array}{l}\text { 2FI vs } \\
\text { Linear }\end{array}$ & 391.92 & 3 & 130.64 & 0.90 & 2.16 & 0.1511 & \\
\hline Quadratic & 450.25 & 3 & 150.08 & & 5.55 & 0.0235 & Suggested \\
\hline $\begin{array}{l}\text { Cubic vs } \\
\text { Quadratic }\end{array}$ & 193.27 & 4 & 48.32 & & 4.32 & 0.0321 & Aliased \\
\hline Residual & 23.23 & 4 & 5.81 & & & & \\
\hline Total & 148231.40 & 20 & $\begin{array}{c}7411.568 \\
08 \\
\end{array}$ & & & & \\
\hline
\end{tabular}

\section{Removal Efficiency Model Selection and Analysis of} Variance

To develop the best-fit equation for removal efficiency, the interaction between the variables and their responses was analyzed using the Central Composite Design (CCD). The standard deviation and correlation coefficient were used to show the validity of the model analyzed (Montgomery, 2009; Abdullah et al., 2014; Francisco, 2014). The ANOVA for removal efficiency with all possible models is shown in Table 3. This analysis indicates that the model involving all terms is significant and the lack of fit is not significant. The model Fvalue of 7.76 implies that the model is significant and that there is only a $0.42 \%$ chance that such a Model F-value could occur

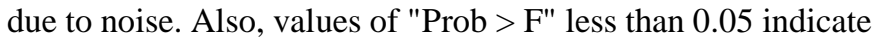
that model terms are significant. In this case, C, BC, $\mathrm{C}^{2}$ are significant models having a $p$-value of less than 0.05 .

Table 3: Analysis of Variance for Oil Removal Efficiency (Complete Model Terms).

\begin{tabular}{lcccccc}
\hline Source & $\begin{array}{c}\text { Sum of } \\
\text { Squares }\end{array}$ & Df & $\begin{array}{c}\text { Mean } \\
\text { Square }\end{array}$ & F Value & $\begin{array}{c}\boldsymbol{p} \text {-value Prob } \\
>\text { F }\end{array}$ & \\
\hline Model & 1890.11 & 9 & 210.01 & 7.76 & $\mathbf{0 . 0 0 4 2}$ & Significant \\
A-pH & 27.41 & 1 & 27.41 & 1.01 & 0.3437 & \\
B-Microbial & 9.92 & 1 & 9.92 & 0.367 & 0.5616 & \\
$\begin{array}{l}\text { Conc. } \\
\text { C-Contact }\end{array}$ & 1010.60 & 1 & 1010.60 & 37.35 & 0.0003 & \\
time & 2.14 & 1 & 2.14 & 0.08 & 0.7856 & \\
AB & 9.72 & 1 & 9.72 & 0.36 & 0.5655 & \\
AC & 380.05 & 1 & 380.05 & 14.04 & 0.0056 & \\
BC & 129.91 & 1 & 129.91 & 4.80 & 0.0598 & \\
$\mathrm{~A}^{2}$ & 3.70 & 1 & 3.70 & 0.14 & 0.7210 & \\
$\mathrm{~B}^{2}$ & 275.85 & 1 & 275.85 & 10.19 & 0.0128 & \\
$\mathrm{C}^{2}$ & 216.50 & 8 & 27.062 & & & significant \\
Residual & 201.40 & 5 & 40.28 & 8.00 & $\mathbf{0 . 0 5 8 7}$ & \\
Lack of Fit & 15.10 & 3 & 5.03 & & & \\
Pure Error & 2139.20 & 19 & & &
\end{tabular}


To adjust the model, the non-significant terms such as A, $\mathrm{B}, \mathrm{AB}, \mathrm{AC}, \mathrm{A}^{2}$, and $\mathrm{B}^{2}$ which are not contributing to its hierarchy were removed, and the adjusted model is presented in Table 4. From the table, the quadratic model established that the model was highly significant for removal efficiency and, this was evident from the low probability $P<0.0001$ of the Fvalue, while the lack-of-fit model was not significant. The model F-value of 14.08 implies that the model is significant and that there is only a $0.01 \%$ chance that a model $\mathrm{F}$ - value this large could occur due to noise. In this case, $\mathrm{C}, \mathrm{BC}$, and $\mathrm{C}^{2}$ are significant model terms. The "Lack of Fit F-value" of 7.55 implies that there is a $6.15 \%$ chance that a "Lack of Fit Fvalue" this large could occur. The model equation obtained from the improved model is presented in Eq. (3).

$-64.64722+21.52996 B+18.22712 C-$

$$
1.96929 B C-0.37582 C^{2}
$$

where:

$$
\begin{aligned}
& \text { A - pH } \\
& \text { B - Microbial concentration (spores/ml) } \\
& \text { C - Contact time (days) }
\end{aligned}
$$

To validate the developed model, statistical features such as $\mathrm{R}^{2}$, adjusted and predicted $\mathrm{R}^{2}$, lack of fit, adequate precision, and residual behaviour were analyzed. The insignificant lack of fit presented in Table 4 implies that the $E_{R}$ model fits adequately with the data (Adebisi, 2016). The summary of the model statistics presented in Table 5 shows the conditions for the adjusted model terms. The $\mathrm{R}^{2}$ for the adjusted model was 0.81 . According to Montgomery (2009), for a model to be adequate in predicting response, the difference between the predicted $\mathrm{R}^{2}$ and the adjusted $\mathrm{R}^{2}$ should be within 0.2 and adequate precision should be greater than 4 .

From the model developed, adequate precision for the adjusted model was 12.36 , the difference between the predicted $\mathrm{R}^{2}$ and the adjusted $\mathrm{R}^{2}$ for the improved model was 0.2 which is within the reasonable range of acceptance (Design Expert 7.0.0). Based on these statistical features, the model is adequate to predict $E_{R}$ behaviour. The coefficient of variation $(\mathrm{CV})$ is the ratio of the standard deviation to mean expressed in percentage. For a model to be considered reliable, its $\mathrm{CV}$ should not be greater than $10 \%$, therefore a CV of $6.45 \%$ obtained may be considered adequate and can, therefore, be used for predicting a response (Agarry, 2017).

Table 4: Analysis of Variance for $E_{R}$ (Adjusted model terms)

\begin{tabular}{lcccccc}
\hline Source & $\begin{array}{c}\text { Sum of } \\
\text { Squares }\end{array}$ & Df & $\begin{array}{c}\text { Mean } \\
\text { Square }\end{array}$ & F Value & $\begin{array}{c}\boldsymbol{p} \text {-value } \\
\text { Prob > F }\end{array}$ & \\
\hline Block & 32.59 & 2 & 16.30 & & & Significant \\
Model & 1711.44 & 4 & 427.86 & 14.08 & $\mathbf{0 . 0 0 0 1}$ & \\
B-Microbial & 9.92 & 1 & 9.92 & 0.33 & 0.5775 & \\
$\begin{array}{l}\text { Concentration } \\
\text { C-Contact time }\end{array}$ & 1010.60 & 1 & 1010.60 & 33.25 & $<0.0001$ & \\
& & & & & & \\
BC & 380.05 & 1 & 380.05 & 12.50 & 0.0037 & \\
C $^{2}$ & 310.86 & 1 & 310.86 & 10.23 & 0.0070 & \\
Residual & 395.17 & 13 & 30.40 & & & \\
Lack of Fit & 380.07 & 10 & 38.01 & 7.55 & $\mathbf{0 . 0 6 1 5}$ & not \\
& & & & & & \\
Pure Error & 15.10 & 3 & 5.03 & & & \\
Total & 2139.20 & 19 & & & & \\
\hline
\end{tabular}

Table 5: Summary of Regression Statistics for $\mathbf{E}_{\mathbf{R}}$.

\begin{tabular}{lc}
\hline Condition & Removal Efficiency \\
\hline R- squared & 0.81 \\
Adjusted R-squared & 0.72 \\
Predicted R-squared & 0.50 \\
Adequate Precision & 12.36 \\
Standard deviation & 5.51 \\
Mean & 85.47 \\
Coefficient of variation $(\%)$ & 6.45 \\
\hline
\end{tabular}




\section{Model Analytical Assessment}

The normal plot of the residuals shown in Figure 1 indicates that the residuals are randomly scattered and approximately followed a straight line pattern. Therefore, the normality condition is satisfied for removal efficiency. This residual shows the nearness of the actual value to the predicted value (Ajani et al., 2017). The plot of residuals against the predicted values of ER in Figure 2 showed that the values analyzed were centred on zero, scattered randomly, and presented a random distribution of positive and negative values, this may suggest that the variances of the original observations are constant for all values. Hence, based on this constant variance, the data is considered to be adequate (Adebisi, 2016).

The run order or time-based sequence of the residuals or randomized experiments demonstrated independence such that all residuals (whether positive or negative) are not correlated (Montgomery, 2009). The plot of residuals over run order or time is used to satisfy this requirement by showing a randomly scattered plot as presented in Figure 3. It is observed that the plot did not exhibit any relationship of data toward any of the two ends. This implies that the independence assumption on the errors is satisfied and the model is adequate to predict $E_{R}$.

Transformations are typically performed in a situation whereby there is a need to stabilize the variance, induce normality, and simplify the model to improve the model fit to the data. This condition occurs when the confidence interval is not unity. It is observed from Figure 4, that the confidence interval is unity $(\lambda=1)$ which means no transformation will be recommended. With this, it is concluded that the normality and residuals are adequate to predict the ER model (Montgomery, 2009; Adebisi, 2016).

\section{E. Model Graph for Removal Efficiency}

The 3-D response surface plots and the corresponding 2-D contour maps generated by the model for ER are shown in Figures 5 to 7 . The plots give the ER trend with simultaneous changes in the significant factors.

The graphical presentations generated by the model for removal efficiency are shown in Figures 5 to 7 . Figure 5 (a) and (b) presents a contour plot and a 3-D surface plot showing an interaction between contact time in days and microbial concentration (spores/ml) on the crude oil removal efficiency when the $\mathrm{pH}$ was kept constant, this plot indicates that both contact time and microbial efficiency had a positive impact on the biodegradation process. It was observed that as factors $\mathrm{B}$ and $\mathrm{C}$ increased, the ER also increased to a certain level within the experimental value range.

Figure 6 (a) and (b) presents a contour plot and a 3-D surface plot showing an interaction between $\mathrm{pH}$ and microbial concentration (spores $/ \mathrm{ml}$ ) on the crude oil removal efficiency when contact time was kept constant, this plot indicates that the interaction between both parameters had a little effect on the removal efficiency, however, as the microbial concentration increased, the ER also increased. Figure 7 (a) and (b) also confirms the positive impact of contact time on removal efficiency. The findings in this work agree with the work done by Ajani et al. (2017), whose report also shows the positive impact of contact time on the bioremediation process.

\section{F. Model Prediction Competency}

Model prediction competency was evaluated from the graph of predicted against the actual values. Figure 8 shows clustered data around the straight line with less variation which indicates that the model is adequate for predicting the response, in this case ER, within the experimental region.

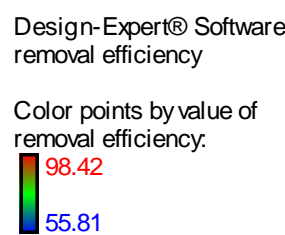

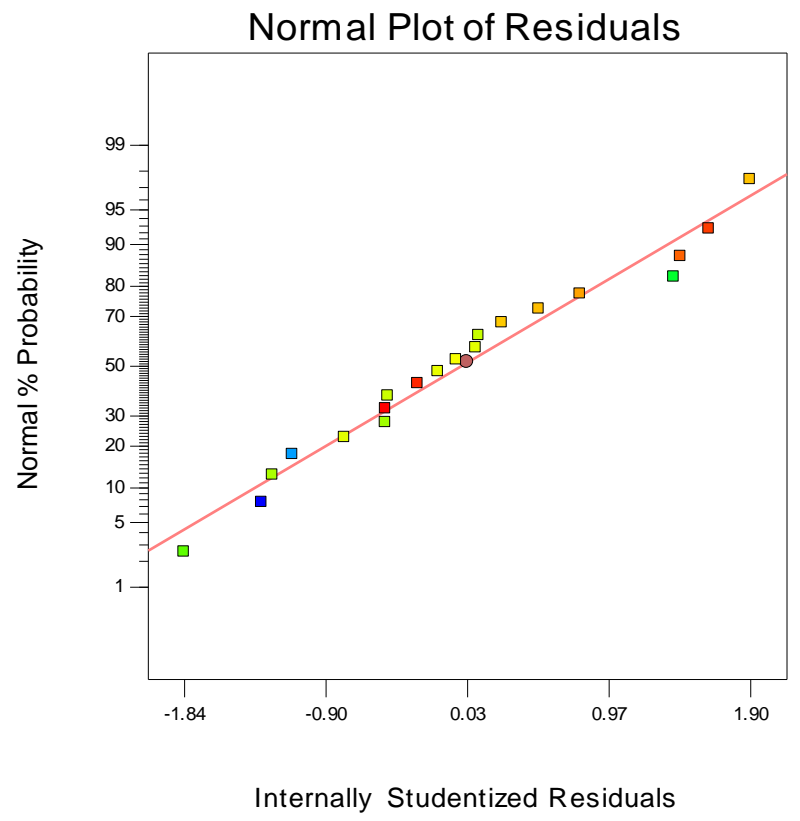

Figure 1: Normal probability plot of residuals. 


\section{Design-Expert@ Software removal efficiency \\ Color points by value of removal efficiency. \\ 98.42 \\ 55.81}

Design-Expert@ Software removal efficiency

Lambda

Current $=1$

Best $=2.87$

Low C.I. $=0.08$

High C.I. $=5.97$

Recommend transform:

None

$($ Lambda $=1)$

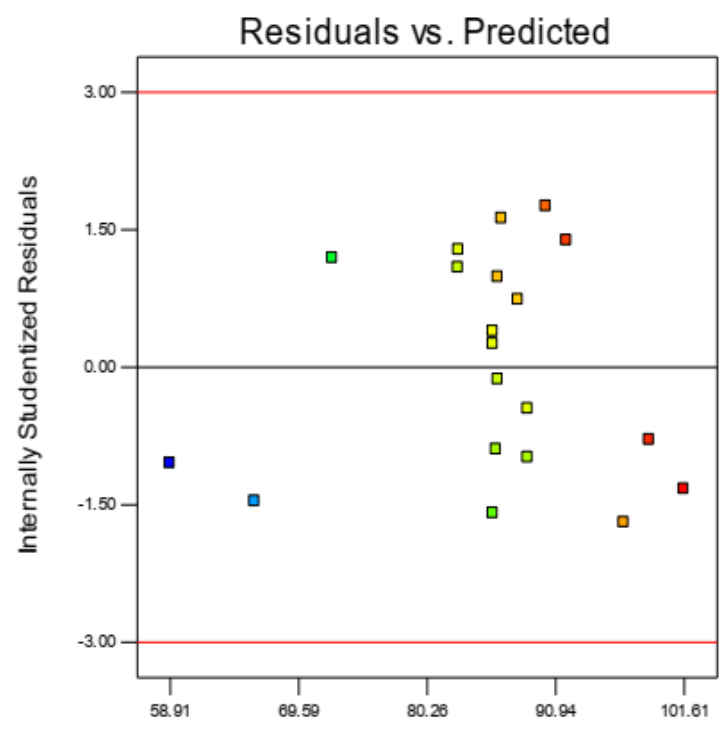

Predicted Figure 2: Plot of Residuals versus predicted values.

Design-Expert@ Software removal efficiency

Color points by value of removal efficiency.

98.42

55.81

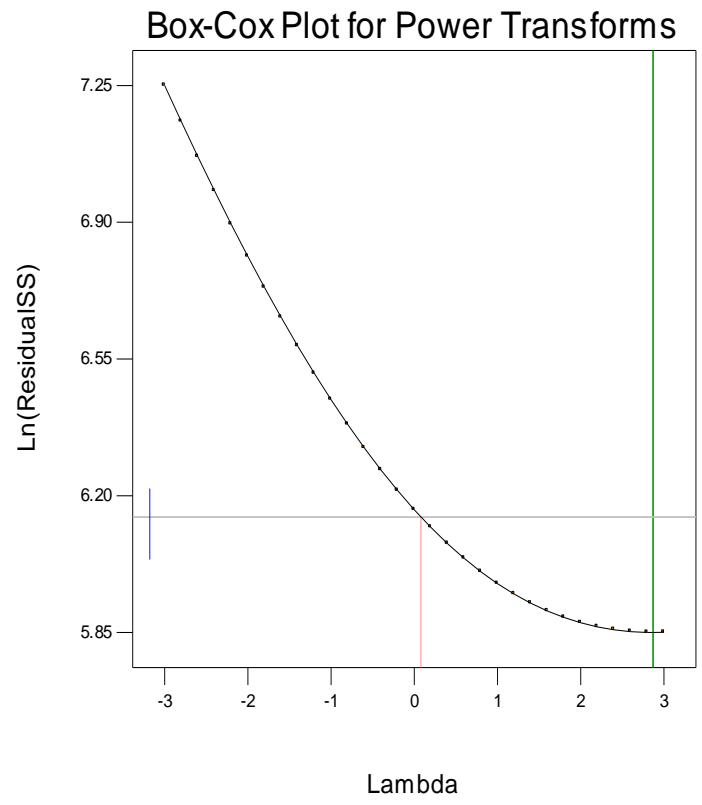

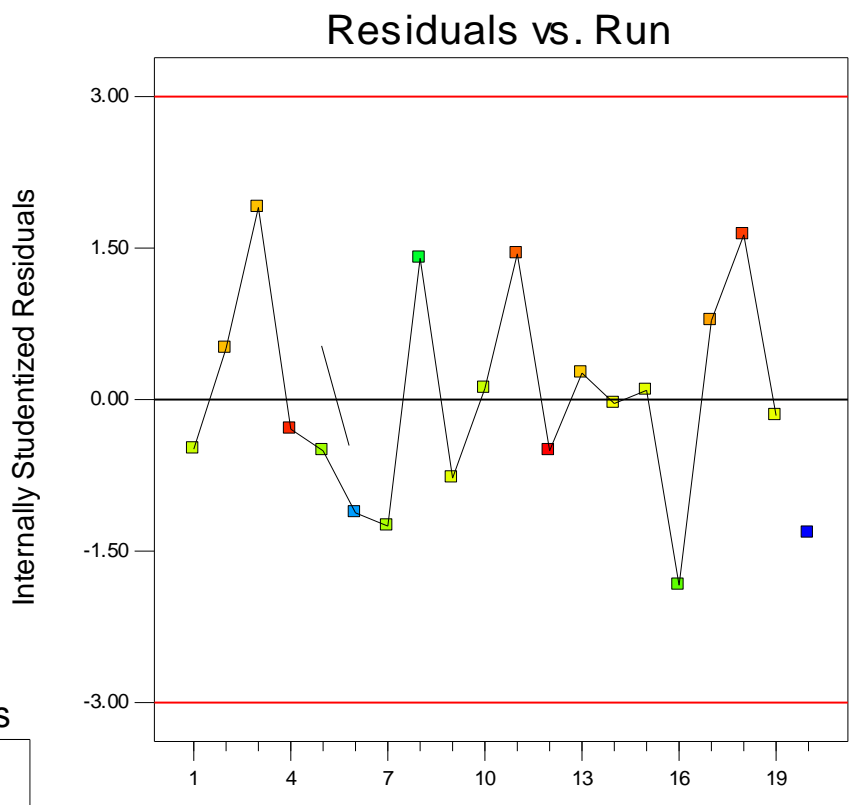

Run Number

Figure 3: Plot of residuals against run order.

Figure 4: Plot of Box-Cox power transformation. 


Design-Expert $\AA$ Software
removal efficiency
$\prod_{55.81}^{98.42}$

$\mathrm{X} 1=\mathrm{B}:$ Microbial Conc X2 = C: Contact time

Actual Factor

$\mathrm{A}: \mathrm{pH}=7.47$

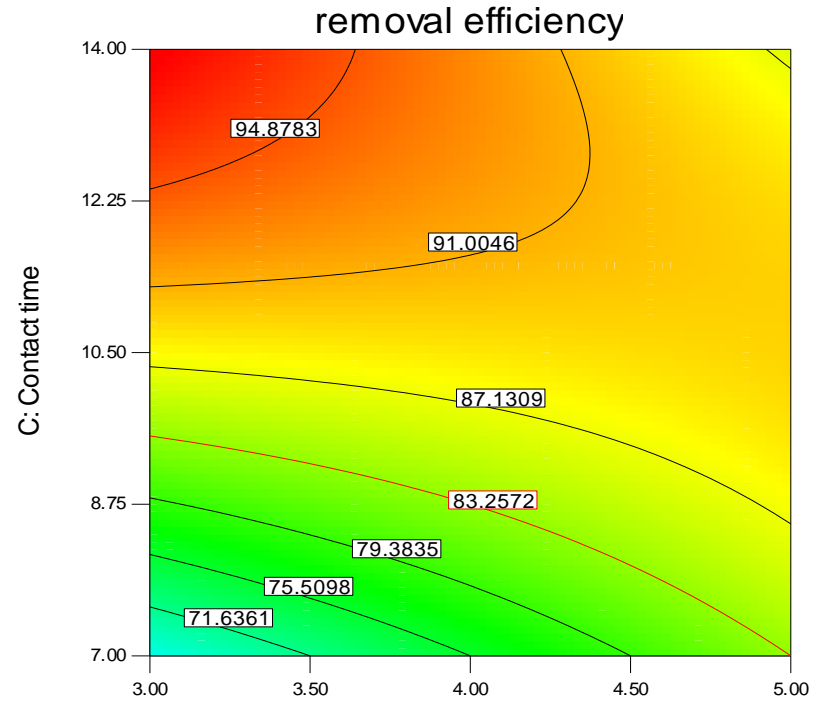

(a)

B: Microbial Conc

Design-Expert@ Software

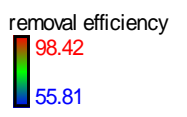

X1 = B: Microbial Conc $\mathrm{X} 2=\mathrm{C}:$ Contact time

Actual Factor

$\mathrm{A}: \mathrm{pH}=7.50$

(b)

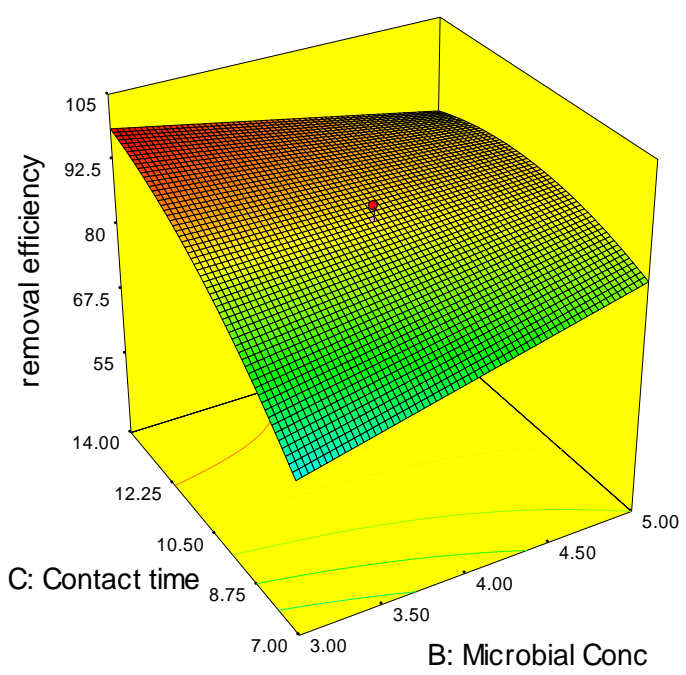

Figure 5: 3-D surface and contour plots of $E_{R}$ with contact time and Microbial concentration. (a) contour map (b) surface plot.

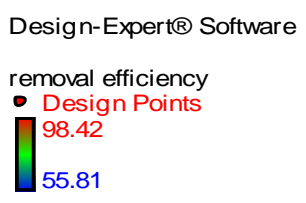

$\mathrm{X} 1=\mathrm{A}: \mathrm{pH}$ $\mathrm{X} 2$ = B: Microbial Conc

Actual Factor C: Contact time $=10.50$

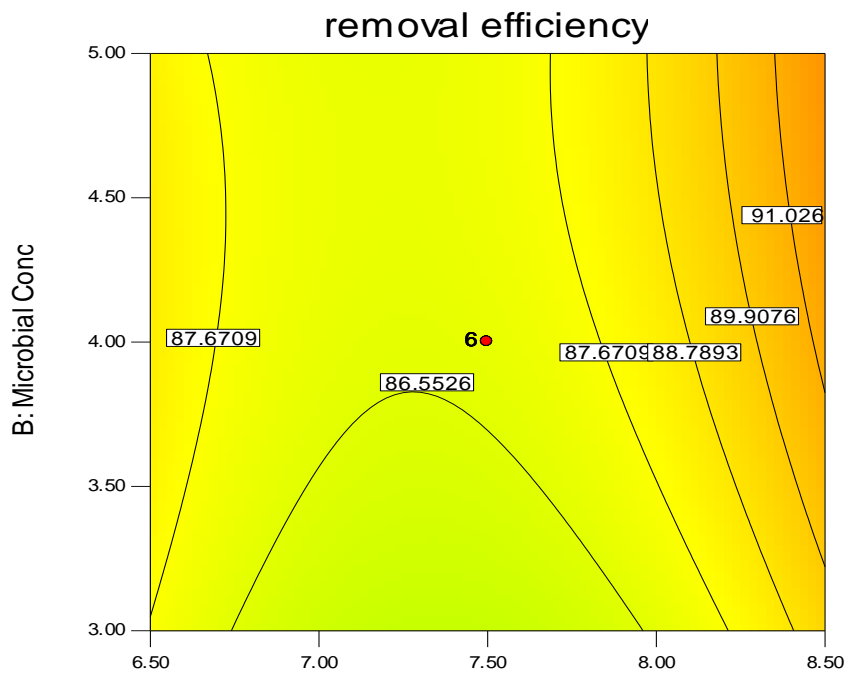

(a) 


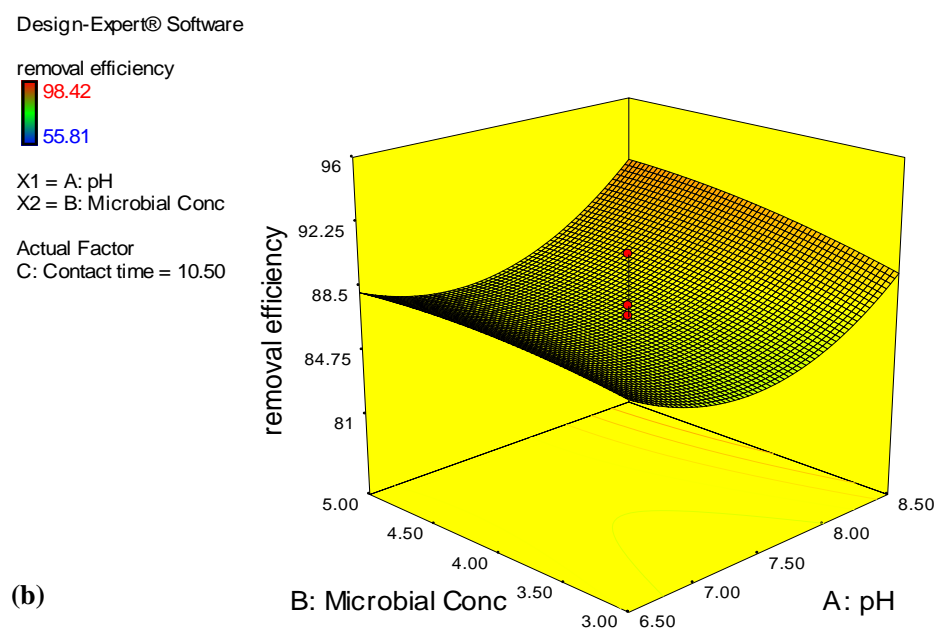

Figure 6: 3-D surface and contour plots of $E_{R}$ with microbial concentration and $\mathrm{pH}$. (a) contour map (b) surface plot.

Design-Expert $\circledast$ Software
removal efficiency
o Design Points
$\prod_{55.81}^{98.42}$
X1 = A: pH
X2 = C: Contact time
Actual Factor
B: Microbial Conc $=4.00$

(a)

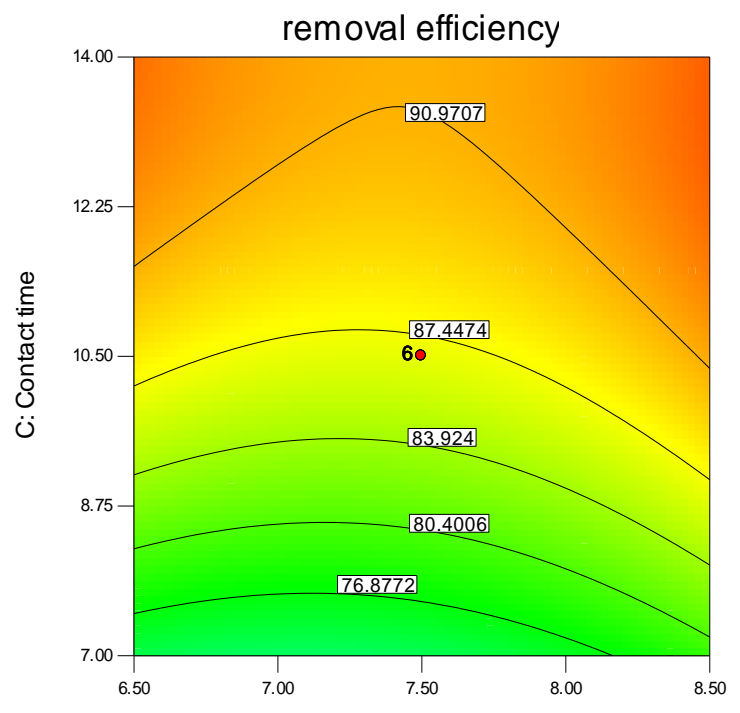

Design-Expertß Software

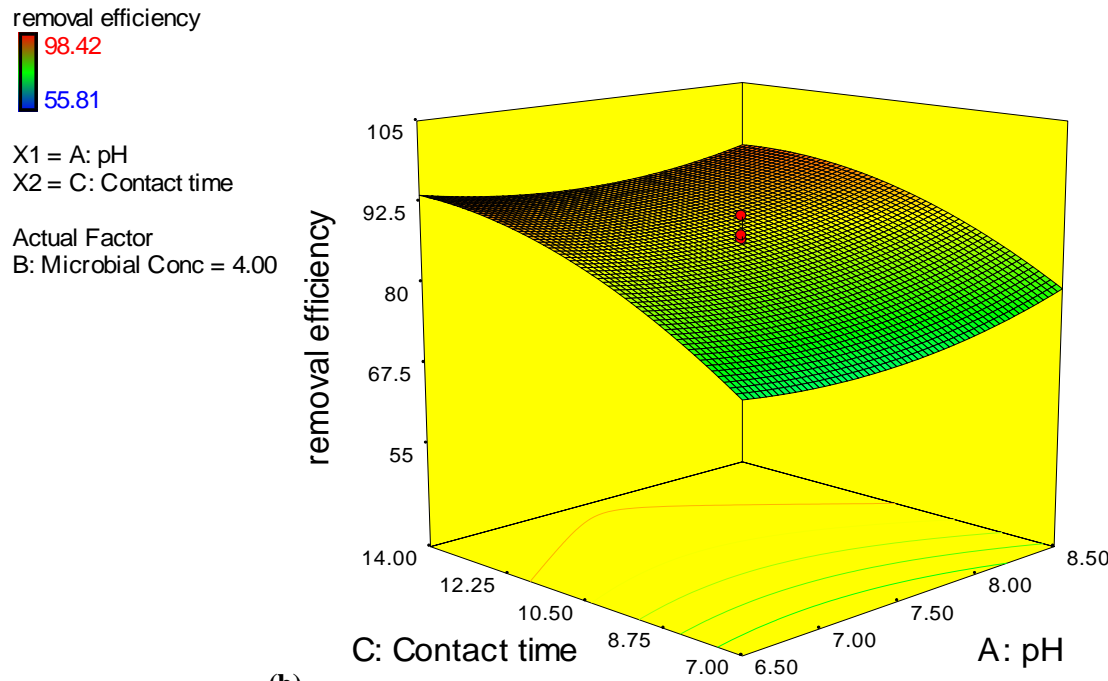

(b)

Figure 7: 3-D surface and contour plots of $\mathrm{E}_{\mathrm{R}}$ with contact time and $\mathrm{pH}$ (a) contour map (b) surface plot. 

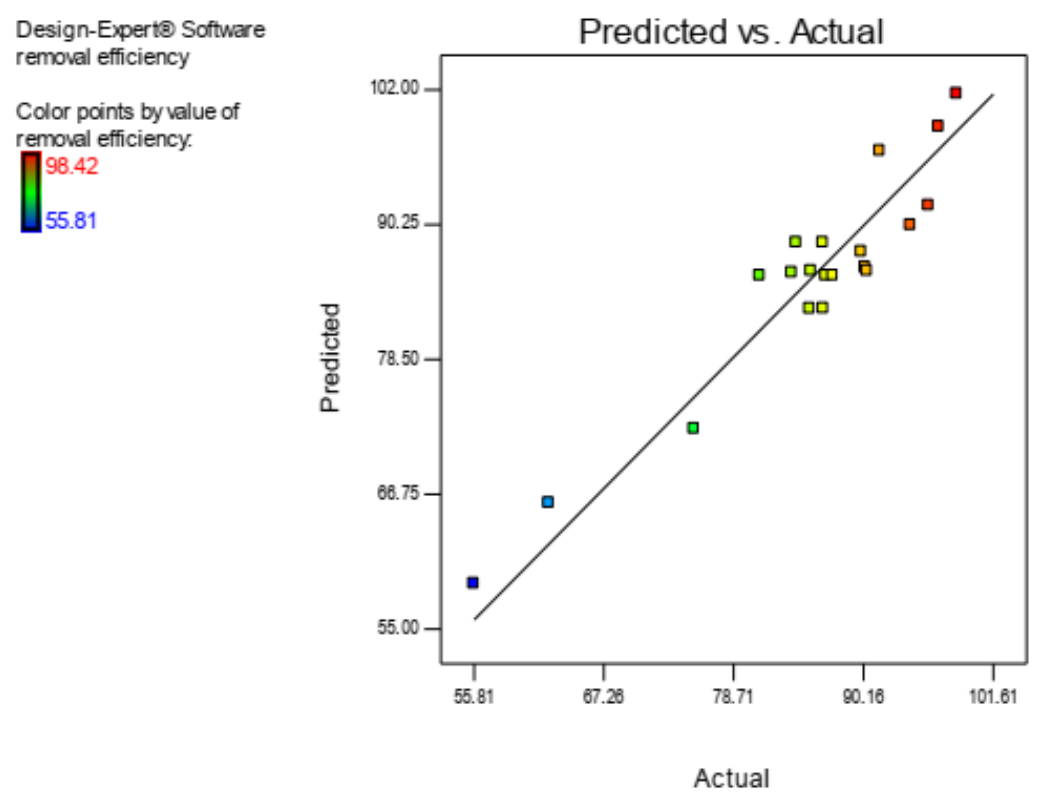

Figure 8: Plot of predicted vs actual for $\mathbf{E}_{\mathrm{R}}$.

\section{G. Optimization and Validation}

Optimization was achieved using a multi-objective numerical optimization technique based on the desirability function. The performance of the optimization analysis achieved a maximum ER of $98.59 \%$ at a contact time of 13.96 days, a $\mathrm{pH}$ of 6.85 , and a microbial concentration of 3.01 spores/ml. For an ideal case of ER optimization, the goal for $\mathrm{pH}$, contact time, and microbial concentration was set in range and oil removal efficiency was set on maximizing (Agarry and Ogunleye, 2012; Adebisi, 2016). Solution No. 1 of Table 6 was therefore selected as the optimum condition. The desirability was 1.00 for the experiment.

\section{H. Validation of Predicted Model using Experimental Results}

Validation of optimum points were achieved using both the model equation and laboratory analysis. The predicted model was obtained using optimum conditions of $\mathrm{pH}$, microbial concentration (spores/ml) and contact time (days) shown in Table 6. The selected conditions were used to calculate the removal efficiency and the same conditions were used to run an experiment in the laboratory for validation of $E_{R}$. From the table, selected optimum removal efficiency (predicted) was $98.59 \%$ (at $\mathrm{A}=6.85, \mathrm{~B}=3.01 \mathrm{spores} / \mathrm{ml}$ and $\mathrm{C}=13.96$ days). This was used to calculate the $\mathrm{E}_{\mathrm{R}}$ (Actual) as shown in Eq. (3). From the equation;

$$
\begin{gathered}
E_{R}=-64.64722+21.52996 B+18.22712 C-1.96929 B C \\
-0.37582 C^{2} \\
E_{R}=-64.64722+(21.52996 \times 3.01)+(18.22712 \times 13.96)- \\
1.96929(3.01 \times 13.96)-0.3758213 .96^{2}=98.62 \%
\end{gathered}
$$

The predicted and actual removal efficiencies of $98.59 \%$ and $98.62 \%$ were used in calculating the standard deviation and percentage error for validation of the experiment. The percentage error between predicted and actual values was calculated according to Eq. (4).

$$
\% \text { Error }=\frac{\text { Actual value }- \text { Predicted Value }}{\text { Actual Value }} \times 100
$$

The percentage error between the predicted and actual values was found to be $0.03 \%$ this clearly shows that no significant difference was observed and this corroborates with the report of Agarry and Ogunleye, (2012) and Ajani et al., (2017). This value indicates that the model developed is valid and can be used in predicting response variables. The optimum conditions obtained for ER was used in the remediation of refinery effluent in the laboratory. After treatments, the removal efficiency of crude oil in the effluent obtained was $99.01 \%$. The percentage error between the experimental and predicted response of the model for ER was 0.4 , the model can, therefore, be used in predicting response variables.

\section{CONCLUSION}

From the research carried out, Monocillium sp. could degrade oil-contaminated effluent as it recorded a high oil removal efficiency of $98.42 \%$. The effects of $\mathrm{pH}$, microbial concentration, and contact time on oil removal efficiency were investigated using RSM. Results from the analysis of variance indicated a significant difference $(p<0.05)$ within and between the final measurements for oil removal. The optimum conditions for the factors investigated were at a contact time of 13.96 days, a $\mathrm{pH}$ of 6.85 , and a microbial concentration of 3.01 spores $/ \mathrm{ml}$. The optimum removal efficiency obtained was $98.59 \%$. The findings of this study revealed that fungi isolated from a hydrocarbon-contaminated environment can be used in hydrocarbon degradation. This can be used as an alternative treatment method when compared to physical and chemical treatment and will also reduce the cost of expensive analysis.

Further research should be carried out on biodegradation analysis to assess the interactions between the native degraders both singly and in the consortium that demonstrate good growth in crude oil to remediate crude oil-contaminated water and soil. Temperature is one of the factors affecting bioremediation and it should be therefore investigated to know 
the optimum temperature necessary for bioremediation to occur, therefore it is important to explore the effect of temperature on other environmental factors like $\mathrm{pH}$, microbial concentration and contact time.

\section{REFERENCES}

AbdelRahman, M. E. (2011). Biodegradation of Crude Oil by Bacteria Isolated from Produced Formation Water of an Onshore Oil Field in Sudan. Masters Thesis Submitted to the Department of Botany, University of Khartoum, Khartoum.

Abdullah, E. M.; A. Hamidi; E. G. S. Nour; A. S. Salem and N. N. Hussein. (2014). Optimization of Libyan Crude Oil Biodegradation by Using Solid Waste Date as a Natural LowCost Material. Journal of Bioremediation and Biodegradation, 5(7): 1-10.

Adebisi, A. A. (2016). Optimization of Stir Casting Process Parameters of Aluminium Silicon Carbide Particulate Composites. A Published Doctoral Dissertation, International Islamic University, Malaysia.

Agarry, S. E. (2017). Statistical Optimization and Kinetic Studies of Enhanced Bioremediation of Crude OilContaminated Marine Water using Combined AdsorptionBiostimulation Strategy. Journal of Science and Environmental Management, 21(1): 59-74.

Agarry, S. E. and Jimoda, L. A. (2013). Application of Carbon-Nitrogen Supplementation from Plant and Animal Sources in In-situ Soil Bioremediation of Diesel Oil: Experimental Analysis and Kinetic Modelling. Journal of Environmental and Earth Science, 3(7): 51-63.

Agarry, S. E. and Ogunleye, O. O. (2012). Factorial Designs Application to Study Enhanced Bioremediation of Soil Artificially Contaminated with Weathered Bonny Light Crude Oil through Biostimulation and Bioaugmentation Strategy. Journal of Environmental Protection, 3(8): 748-759.

Ajani, O. A.; O. O. Ogunleye and J. O. Hamed. (2017). Enhanced Bioremediation of Soil Contaminated with Anthracene: Optimization of Biostimulant Levels using Response Surface Methodology. Journal of Applied and Natural Science, 2(1): 7-30.

Al-Hawash, A. B.; J. T. Alkooranee; H. A. Abbood; J. Zhang; J. Sun; X. Zhang and F. Ma. (2018). Isolation and Characterization of Two Crude Oil Degrading Fungi Strains from Rumaila Oil Field, Iraq. Biotechnology Reports, 17(1): 104-109.

April, T. M.; J. M. Fought, and R. S. Currah. (2000). Hydrocarbon-Degrading Filamentous Fungi Isolated from Flare Pit Soils in Northern and Western Canada. Canadian Journal of Microbiology, 46(1): 38-49.

Barnes, N. M.; V. B. Khosde; N. P. Lotlikar; R. M. Meena and S. R. Damare. (2018). Bioremediation Potential of Hydrocarbon-Utilizing Fungi from Select Marine Niches of India. Journal of Biotechnology, 8(1): 21-25.

Ekundayo, O. F.; F. O. Olukunle and E. A. Ekundayo. (2012). Biodegradation of Bonnylight Crude Oil by Locally Isolated Fungi from Oil Contaminated Soils in Akure, Ondo State. Malaysian Journal of Microbiology, 8(1): 42-46.
El-Sheshtawy, H. S.; N. M. Khalil; W. Ahmed and A. A. Nabila. (2017). Enhancing the Bioremediation of Crude Oil by Nanoparticle. Egyptian Journal of Chemistry, 60(5): 835-848.

Francisco, G. (2014). Assessment and Optimization of ExSitu Bioremediation of Petroleum Contaminated Soil under Cold Temperature. A Master's Thesis Submitted to the Department of Civil Engineering, University of Ottawa, Canada.

Ibrahim, F. B. (2008). Bioremediation of Abattoir Wastewater using Immobilized Cells of Aspergillus niger. An Unpublished Master's Thesis Submitted to the Department of Water Resources and Environmental Engineering, Ahmadu Bello University, Zaria.

Isaac, A. M. (2018). Bioremediation of Hydrocarbon Polluted Soil using Pseudomonas aeruginosa. An Unpublished Master's Thesis Submitted to the Department of Water Resources and Environmental Engineering, Ahmadu Bello University, Zaria.

Joutey, N. T.; W. Bahafid; H. Sayel and N. El Ghachtouli. (2013). Biodegradation: Involved Microorganisms and Genetically Engineered Microorganisms. Biodegradation Life of Science, 11(2): 290-308.

Majekodunmi, A. O. and Adongbede, E. M. (2016). Biodegradation of Crude Oil using Aspergillus niger Isolated from the Rhizosphere of Helianthus annuus. Research Journal of Agriculture and Environmental Management, 5(4): 132137.

McDonald, J. A. (2001). Evaluation of In-Situ Bioremediation Approaches in Meeting International Standards for Organic and Residual Metals Toxicity in Soils. A Published Master's Thesis Submitted to the Graduate Faculty of the Lousiana State University and Agricultural and Mechanical College, Lousiana State University.

Mittal, A. and Singh, P. (2009). Studies on Biodegradation of Crude Oil by Aspergillus niger. The South Pacific Journal of Natural Science. 27(1): 57-60.

Montgomery, D. C. (2009). Introduction to Statistical Quality Control. Third Edition, John Wiley \& Sons.

Nilanjana, D. and Preethy, C. (2011). Microbial Degradation of Petroleum Hydrocarbon Contaminants: An Overview. Biotechnology Research International, 20(11): 113.

Nwachi, E. O.; E. B. Essien and E. Ugbeyide. (2013). Characterization of Warri Refinery Effluent and its Recipient Medium. International Journal of Pure \& Applied Bioscience, 1(4): 22-27.

Nwachukwu, S. U. (2000). Enhanced Rehabilitation of Tropical Aquatic Environment Polluted with Crude Petroleum using Candida utilis. Journal of Environmental Biology, 241250.

Olabisi, P. A.; A. A. Olabimpe and J. J. Udeme. (2009). Biodegradation of Crude Oil in Soil Amended with Melon Shell. AU J.T, 13(1): 34-38.

Olukunle, O. F. and Oyegoke, T. S. (2016). Biodegradation of Crude Oil by Fungi Isolated from Cow Dung Contaminated Soils. Nigerian Journal of Biotechnology, 31(1): 46-58. 
Onifade, A. K.; F. A. Abubakar and F. O. Ekundayo. (2007). Bioremediation of Crude Oil Polluted Soil in the Niger Delta Area of Nigeria Using Enhanced Natural Attenuation. Research Journal of Applied Sciences, 2(2): 498-504.

Orjiude, J. E. (2018). Accessing the Capacity of Wild and Mutant Strains of Bacillus subtilis and Pseudomonas putida Isolated from Refinery Effluent in the Degradation of Hydrocarbons. An Unpublished Master's Thesis Submitted to the Department of Microbiology, Ahmadu Bello University, Zaria, Nigeria.

Prenafeta-Boldu, F. X.; A. Kuhn; D. M. Luykx; H. Anke; J. W. Groenestijn and J. A. De Bont. (2001). Isolation and Characterization of Fungi Growing on Volatile Aromatic Hydrocarbons as their Sole Carbon and Energy Source. Mycology Research Journal, 105(4): 477-484.

Raji, H. M. (2016). Characterization and Molecular Diversity of Some Soil Prokaryotes with Potentials for

Polycyclic Aromatic Hydrocarbon Degradation. An Unpublished Doctoral Dissertation Submitted to the Department of Microbiology, Ahmadu Bello University, Zaria, Nigeria.

Wilde, J. (2017). How do we clean oil spills [Motion Picture]. Images by Thinkstock and Corbis. Retrieved from: https://www.youtube.com/watch?v=3DbSIAg3F3A 